\title{
Extensão universitária na interface virtual: estratégias de aprimoramento docente e discente do curso de fisioterapia da Universidade Federal de Minas Gerais (UFMG)
}

\author{
University extension in virtual spaces: strategies for the development of \\ physical therapy teachers and students at the Federal University in Minas \\ Gerais (UFMG)
}

Fabiane Ribeiro Ferreira ${ }^{1}$ (D) Érica de Matos Reis Ferreira ${ }^{2}$ (D), Daniela Virgínia Vaz ${ }^{1}$ (D)

\begin{abstract}
RESUMO:
A pandemia causada pelo COVID-19, em 2020, resultou no esvaziamento das salas de aula como estratégia de distanciamento para a controle da disseminação do vírus. As universidades, através de seus gestores e docentes, buscaram maneiras de viabilizar a continuidade das atividades acadêmicas pautando-se na cooperação, solidariedade e inovação. Foi imprescindível buscar aprimoramentos para desenvolver o processo de aprendizagem no formato de Ensino Remoto Emergencial (ERE). Neste cenário, a extensão universitária cumpriu um importante papel. Este trabalho relata o processo de criação dos projetos Aprimoramento Docente para Ensino Superior da Fisioterapia (ADES-FIT) e Aprimoramento Discente para o Ensino Superior (ADES Jr.), seus objetivos e atividades realizadas. Acredita-se que iniciativas pautadas na colaboração e com o envolvimento ativo para o aprendizado possam ressignificar as experiências no contexto da universidade.
\end{abstract}

Palavras-chave: Educação; Fisioterapia; Educação continuada; Saúde; Pandemia; Covid-19

\begin{abstract}
:
During the COVID-19 pandemic in 2020, classrooms were emptied to ensure social distancing as a strategy to decrease the spread of the virus. University managers and professors looked for means to continue academic activities through cooperation, solidarity, and innovation. Fast skill building was needed to make remote learning feasible. In this scenario, university extension played an important role. This paper reports on creating and adapting two extension projects to support teachers' and students' skill-building for remote learning, the projects' objectives, and the activities carried out. We believe that collaborative initiatives based on active learning can give new meaning to university activities during challenging times.
\end{abstract}

Keywords: Education; Physical therapy; Continuing education; Health; Pandemic; Covid-19

\section{MENSAGENS IMPORTANTES:}

- O ensino remoto apresentou-se como um grande desafio para a comunidade universitária.

- Estratégias colaborativas de aprimoramento docente e discente ressignifica- ram as experiências no processo ensino-aprendizagem.

- $\quad$ Os projetos de extensão ADES-FIT e ADES Jr. cumpriram importante papel no compartilhamento de ferramentas para viabilizar a educação significativa à distância.

1. PhD. Universidade Federal de Minas Gerais (UFMG), Belo Horizonte, MG. Brasil

2. Msc. Universidade Federal de Minas Gerais (UFMG), Belo Horizonte, MG. Brasil 


\section{A PANDEMIA MODIFICANDO OS MO- DOS DE CONCEBER E VIVENCIAR O PROCESSO ENSINO-APRENDIZAGEM}

A pandemia da COVID-19 instalada em 2020 trouxe impactos sociais importantes e obrigou a população do mundo inteiro a se adaptar e criar um novo modo de viver. Isolados uns dos outros e ainda assustados com as notícias e o futuro incerto, atores das diversas áreas e camadas sociais viram-se obrigados a analisar as situações do momento e decidir como enfrentar a nova realidade.

Nesse cenário, as universidades foram esvaziadas, o que exigiu que gestores e professores, numa construção coletiva, elaborassem um plano capaz de suprir a lacuna do encontro presencial entre professor, aluno e escola ${ }^{1-3}$. Era hora de retomar os conhecimentos didáticos pedagógicos existentes para aperfeiçoá-los, aproveitar a oportunidade para aprender algo novo e principalmente compartilhar saberes com o objetivo solidário de unir forças e deixar a forma de ensinar e aprender mais leve, garantindo a qualidade do aprendizado. Um novo modelo de ensino foi criado de forma compartilhada, considerando que todos estariam distantes da sala de aula presencial.

Surgiu, então o ensino remoto emergencial (ERE), modalidade que muitas instituições de ensino superior adotaram como estratégia. Remoto, uma vez que para conter a propagação do SARS-CoV-2 era necessário o distanciamento, o que impedia a ocupação dos espaços físicos. Emergencial pelas circunstâncias com que os planos pedagógicos precisaram ser refeitos ${ }^{4}$. É indispensável enfatizar que ERE não é sinônimo de Educação a distância (EaD). Na EaD a preparação da disciplina ou curso, desde sua concepção até as formas de organização do processo ensino-aprendizagem estão previstas para ocorrer de forma remota ${ }^{5}$. No ERE há uma adaptação urgente das ferramentas didático pedagógicas como alternativa para o prosseguimento das atividades acadêmicas $^{2}$. Portanto, o desafio no campo da educação apresentava-se ainda maior para os professores com experiência apenas na modalidade presencial de ensino, uma vez que as interações passaram a acontecer em uma interface virtual, que transfor- mou a sala de aula em tela de aula. A necessidade incontestável de mediação da tecnologia para a continuidade das atividades de ensino-aprendizagem era evidente. Nesse sentido, tornou-se necessária a busca imediata de ferramentas para aprender a construir esta nova variante de ensino, integralmente permeada pela tecnologia digital de informação e comunicação com o uso da internet ${ }^{6}$.

É importante salientar que o ERE se apresentou como um grande desafio não só para os docentes, mas também para os discentes. Além das questões relacionadas à desigualdade de acesso à internet e a aparelhos compatíveis com as exigências das plataformas de ensino, a nova modalidade evidenciou a necessidade de discentes desenvolverem, entre outras competências, o protagonismo no processo de aprendizagem ${ }^{3}$. Emergiu, portanto, a demanda de aprimoramento e adaptação não só para os docentes, mas também para os alunos, de forma a garantir o êxito das iniciativas propostas para o ERE.

No curso de Fisioterapia da Universidade Federal de Minas Gerais o projeto "Aprimoramento Docente para o Ensino Superior da Fisioterapia" (ADES-FIT) foi uma das ferramentas que auxiliou principalmente professores a refletirem e enfrentarem o desafio de "aprender a ensinar" e "aprender e ensinar" neste contexto. O contexto da pandemia ensejou rapidamente a criação da versão virtual do ADES e operacionalizou a versão dedicada aos estudantes. O objetivo deste artigo é apresentar os projetos de extensão ADES e relatar a experiência das atividades de capacitação proporcionadas através de seus encontros.

\section{APRIMORAMENTOS DOCENTE E DISCENTE POR MEIO DA EXTENSÃO UNIVERSITÁRIA: ENFRENTANDO DE- SAFIOS JUNTOS.}

A preparação de discentes e docentes para o ERE ficou a cargo da instituição de ensino. Diversas iniciativas de formação foram colocadas à disposição, principalmente dos docentes, em inúmeras modalidades: minicursos, webinars, lives, seminários, entre outros. No entanto, pôdese perceber que as demandas do corpo docente 
dos vários departamentos não eram homogêneas e suas especificidades precisavam ser atendidas. Em um mesmo grupo de professores era possível encontrar aqueles que já utilizavam as técnicas de metodologias ativas de educação em atividades não presenciais e outros com total desconhecimento sobre a plataforma de suporte para o ensino disponibilizada pela instituição. As dificuldades em lidar com as ferramentas necessárias para produzir uma videoaula eram frequentes, ainda que este recurso fosse fundamental na operacionalização do ERE dentro das normativas da Pró -Reitoria de Graduação. Nesse sentido, projetos voltados para a capacitação docente que já existiam no âmbito de alguns departamentos da instituição ganharam visibilidade e adesão por causa da urgência de desenvolver novas competências de atuação docente diante da crise sanitária.

\section{Aprimoramento de competências para docentes}

Este foi o cenário em que o projeto de extensão ADES-FIT (Figura 1) ganhou destaque dentro da instituição. Inicialmente desenhado com foco no corpo docente do departamento de Fisioterapia da Universidade Federal de Minas Gerais (UFMG), o projeto, antes mesmo da pandemia, caminhava com a ampliação de seu público para além dos muros da escola e da universidade. Profissionais da saúde com função de preceptores em estágios obrigatórios do curso, professores de outros departamentos e de outras instituições de ensino superior, pesquisadores da área da educação e alunos do curso de pós-graduação participavam das atividades e capacitações promovidas pelo projeto.

Essa ação extensionista nasceu em 2017, tendo como ponto motivador as reuniões pedagógicas promovidas pelo colegiado de graduação em Fisioterapia por ocasião da implementação do novo currículo do curso. Sua pedra angular foi o empenho dos docentes em alinhar os conteúdos e práticas de cada disciplina do novo currículo ao seu senso compartilhado de identidade profissional: o que é fisioterapia e o que faz um fisioterapeuta?

Foi a partir destas questões que cada professor foi convidado a refletir e identificar quais as competências fundamentais que seus alunos deveriam adquirir com o curso que ministravam. Esse exercício desvelou carências e necessidades de conhecimentos acerca da temática da educação do ensino superior, ensejando a criação do ADESFIT para a capacitação permanente dos docentes.

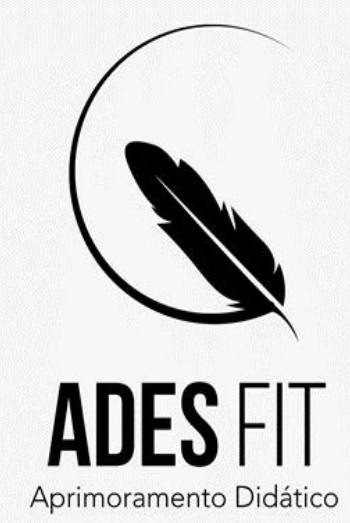

https://instagram.com/adesfit.cre?igshid=s8i7dv7rs8no

Figura 1: Logomarca e perfil do ADES

A proposta principal do ADES-FIT é favorecer a troca de experiências. Acredita-se que os encontros entre atores com experiências variadas no ensino e nas outras áreas do saber viabilizam e facilitam a exposição e acesso a ferramentas de aprimoramento didático, já que os docentes apresentam carga de trabalho elevada e múltiplas atribuições. O resultado dos encontros é a possibilidade de maior integração entre os docentes e a contribuição para o ensino interdisciplinar.

O ADES-FIT tem como objetivos específicos: promover o desenvolvimento docente quanto às recentes tecnologias didáticas; contribuir para o aprendizado e a reflexão docente em relação às formas de avaliação de competências: conteúdo, habilidades e atitudes discentes; propiciar o encontro entre profissionais dos serviços de saúde e de outros serviços e docentes do ensino superior; fomentar o aprimoramento técnico de preceptores e parceiros dos serviços de saúde; proporcionar o aprimoramento docente dos alunos de pósgraduação dos diversos cursos da UFMG; apoiar os docentes do departamento de fisioterapia em relação à atualização de conteúdos relacionados às suas diversas áreas de atuação. 
Ao longo de sua existência, o ADES possibilitou 14 encontros (seis no formato online) com diferentes temas relacionados à docência, envolvendo 18 palestrantes alcançando aproximadamente 500 ouvintes. Os encontros que eram prioritariamente presenciais, na Escola de Educação Física, Fisioterapia e Terapia Ocupacional, em virtude do distanciamento social, tornaram-se virtuais a partir de junho de 2020. Vale destacar que o projeto acolheu a Oficina "Desenvolvimento Docente para a Avaliação Programática do Estudante em Cursos de Graduação da Área da Saúde no Brasil", um consórcio interinstitucional sob a coordenação de docentes da Faculdade de Medicina de Ribeirão Preto da Universidade de São Paulo (FMRP-USP). Os encontros realizados pelo ADES no formato presencial e virtual, seus temas e convidados são apresentados na tabela 1 .

Tabela 1: Temas, datas, convidados e modalidade dos encontros do ADES-FIT

\begin{tabular}{|c|c|c|c|}
\hline TEMAS & $\begin{array}{l}\text { DATA } \\
\text { Dia/mês/ano }\end{array}$ & CONVIDADO & MODALIDADE \\
\hline $\begin{array}{l}\text { Preceptoria nos serviços } \\
\text { com foco no feedback ao } \\
\text { discente }\end{array}$ & $19 / 06 / 2018$ & $\begin{array}{l}\text { Eliane Gontijo } \\
\text { Professora da Escola de Medi- } \\
\text { cina da UFMG }\end{array}$ & Presencial \\
\hline $\begin{array}{l}\text { Aprendizagem Baseada em } \\
\text { Equipes e Instrução por } \\
\text { pares }\end{array}$ & $30 / 10 / 2018$ & $\begin{array}{l}\text { Daniela Vaz } \\
\text { Professora do Departamento } \\
\text { de Fisioterapia da UFMG }\end{array}$ & Presencial \\
\hline $\begin{array}{l}\text { Amor educativo e aprendi- } \\
\text { zagem significativa }\end{array}$ & $23 / 04 / 2019$ & $\begin{array}{l}\text { Tarcísio Ramos Homem } \\
\text { Professor da Escola de Belas } \\
\text { Artes da UFMG }\end{array}$ & Presencial \\
\hline $\begin{array}{l}\text { Comunicação não violenta } \\
\text { na sala de aula }\end{array}$ & $28 / 05 / 2019$ & $\begin{array}{l}\text { Gabriel Rodrigues } \\
\text { Membro da Ciranda - Justiça } \\
\text { Restaurativa, } \\
\text { Faculdade de Direito da UFMG }\end{array}$ & Presencial \\
\hline $\begin{array}{l}\text { Desenvolvimento Docente } \\
\text { para a Avaliação Programá- } \\
\text { tica do Estudante em Cursos } \\
\text { de Graduação da Área da } \\
\text { Saúde no Brasil }\end{array}$ & $\begin{array}{l}08 \mathrm{e} \\
09 / 08 / 2019\end{array}$ & $\begin{array}{l}\text { Valdes Bollela } \\
\text { Anamaria Siriani } \\
\text { Marcos Borges } \\
\text { Maria Paula Panúncio } \\
\text { Professores da (FMRP-USP) }\end{array}$ & Presencial \\
\hline $\begin{array}{l}\text { Humor na educação: rir é } \\
\text { próprio do homem }\end{array}$ & $17 / 09 / 2019$ & $\begin{array}{l}\text { Priscila Araújo } \\
\text { Fisioterapeuta, Pós Doc do } \\
\text { Programa de Ciências da Rea- } \\
\text { bilitação UFMG }\end{array}$ & Presencial \\
\hline Gestão de Conflitos & $22 / 10 / 2019$ & $\begin{array}{l}\text { Cristina Alvim } \\
\text { Professora da Escola de Me- } \\
\text { dicina }\end{array}$ & Presencial \\
\hline $\begin{array}{l}\text { Métodos de Ensino para a } \\
\text { geração } Y\end{array}$ & $19 / 11 / 2019$ & $\begin{array}{l}\text { Luciano Fonseca Oliveira } \\
\text { Professor do Departamento } \\
\text { de Fisioterapia da UFMG }\end{array}$ & Presencial \\
\hline $\begin{array}{l}\text { Ferramentas para o ensino } \\
\text { remoto emergencial: cons- } \\
\text { truindo vídeo aula no power } \\
\text { point e uma sala no Micro- } \\
\text { soft Teams. }\end{array}$ & $16 / 06 / 2020$ & $\begin{array}{l}\text { Daniela Vaz e Fernanda Lan- } \\
\text { za; Professoras do depar- } \\
\text { tamento de Fisioterapia da } \\
\text { UFMG }\end{array}$ & Virtual - Microsoft Teams ${ }^{\mathrm{TM}}$ \\
\hline
\end{tabular}


Tabela 1

(continuação)

\begin{tabular}{|c|c|c|c|}
\hline $\begin{array}{l}\text { Processo de avaliação a } \\
\text { distância }\end{array}$ & $25 / 062020$ & $\begin{array}{l}\text { Anamaria Siriani de Oliveira } \\
\text { Professora da (FMRP-USP) }\end{array}$ & $\begin{array}{l}\text { Virtual - Instagram } \\
\text { https://www.instagram.com/ } \\
\underline{\text { tv/CB37bU9JTEk/?igshi- }} \\
\underline{\mathrm{d}=3 \text { wllustil11i }}\end{array}$ \\
\hline $\begin{array}{l}\text { Educação em saúde: refle- } \\
\text { xões de sua evolução ao } \\
\text { longo do tempo }\end{array}$ & $30 / 06 / 2020$ & $\begin{array}{l}\text { Magda Rocha } \\
\text { Professora de Fisioterapia } \\
\text { PUC Minas }\end{array}$ & $\begin{array}{l}\text { Virtual - Instagram } \\
\text { https://www.instagram.com/ } \\
\underline{\text { tv/CCFB4fnpXf5/?igshid=oy- }} \\
\underline{\text { zovntoeik8 }}\end{array}$ \\
\hline Mapas Conceituais & $17 / 07 / 2020$ & $\begin{array}{l}\text { Fernanda Saltiel } \\
\text { Professora de Fisioterapia Fa- } \\
\text { culdade de Ciências Médicas } \\
\text { MG }\end{array}$ & Virtual - Zoom \\
\hline $\begin{array}{l}\text { Más práticas acadêmicas e } \\
\text { plagiarismo: reflexões da } \\
\text { integridade acadêmica no } \\
\text { ensino superior }\end{array}$ & $28 / 07 / 2020$ & $\begin{array}{l}\text { Thiago Henrique Lobato de } \\
\text { Araújo } \\
\text { Professor de Fisioterapia da } \\
\text { UNA }\end{array}$ & $\begin{array}{l}\text { Virtual - Instagram } \\
\text { https://www.instagram.com/ } \\
\text { tv/CDNBaXwJRHm/?igshid=- } \\
\underline{\text { d4xjc6bugriq }}\end{array}$ \\
\hline $\begin{array}{l}\text { O teatro e a linguagem cor- } \\
\text { poral: o que a fisioterapia } \\
\text { tem a ver com isso? }\end{array}$ & $18 / 08 / 2020$ & $\begin{array}{l}\text { Reginaldo Santos, Coordena- } \\
\text { dor do projeto Sociocultural } \\
\text { Conexão Galpão e do Progra- } \\
\text { ma de Ações Formativas em } \\
\text { Teatro do Galpão Cine Horto }\end{array}$ & $\begin{array}{l}\text { Virtual - Instagram } \\
\text { https://www.instagram.com/ } \\
\text { tv/CEDGEvAJxu1/?igshid=- } \\
\underline{\text { mafskyyn39op }}\end{array}$ \\
\hline
\end{tabular}

A adequação entre a concepção do projeto, seus objetivos e o contexto pandêmico na educação superior agregou valor e importância à ação. $O$ ADES-FIT não poderia deixar de cumprir seu papel de compartilhar saberes na área da docência superior, principalmente em um momento tão difícil e de profundas transformações no trabalho docente. Seria mais uma oportunidade para ampliar o aprendizado, partilhar experiências e encontrar apoio entre pessoas comprometidas com a educação.

A partir das ações desenvolvidas pode-se observar o espaço do encontro em toda a sua potencialidade, aproximando de forma efetiva docentes de diversas instituições e cursos, estes e alunos de pós-graduação, em uma troca de informações intensa de um processo genuinamente colaborativo. Este momento de destaque resultou na participação dos coordenadores do projeto em comissões e eventos sobre educação ao nível institucional, entre os quais o Programa Integração Docente de ações formativas para as práticas pedagógicas criado pela UFMG através da Diretoria de Inovação e Metodologias de Ensino (GIZ/Prograd).

\section{Aprimoramento de competências para discentes}

O momento demandava, e ainda demanda, planejamento pautado nas necessidades não apenas de professores, mas também capacitação de estudantes para utilizar recursos tecnológicos de forma efetiva. A necessidade de uma comunicação mais estreita e colaborativa entre professores e discentes, as demandas de ordem prática para viabilizar a participação democrática de discentes no ERE e as questões relacionadas à saúde mental dos estudantes catalisaram a implementação de uma versão do projeto que já vinha sendo planejado para os estudantes: o ADES Jr.

Embora protagonizado por graduandos do curso de Fisioterapia, o ADES Jr. ampliou-se para uma ação interprofissional, uma vez que o curso funciona em uma unidade da universidade que hospeda também os cursos de Terapia Ocupacional e Educação Física. Com o envolvimento de estudantes e docentes dos três cursos, o projeto iniciou suas ações no início de setembro de 2020 
com a finalidade de ser um espaço democrático de autoconhecimento e desenvolvimento pessoal dos discentes. As atividades apresentaram-se em novas formas de aprimorar-se na diversidade de contextos da vida, tendo como pano de fundo a pandemia do COVID-19.

A proposta, protagonizada pelos alunos, aposta em uma alternativa de vivência acadêmica em que o estudante tenha a oportunidade de desenvolver-se: como ser humano que pratica a autorreflexão e a autoconsciência; como agente que toma rédeas de seu processo formativo e reflete sobre as estratégias para a aprendizagem e como cidadão que se integra com a comunidade e provoca mudanças. Com o slogan "ideias que saem do papel e ganham o mundo" e a logomarca um avião de papel lançado ao vento, os alunos construíram a identidade do espaço (ver figura 2). Segundo eles: "a estagnação é uma escolha que se faz todos os dias, como também quando o aluno se satisfaz com o que lhe é dado, com o que Ihe é ensinado. Colaborando para romper as barreiras do conhecimento, a proposta é trazer vida ao cotidiano, seja por meio da arte, da cultura ou por troca de experiências. Também se faz necessário a compreensão do estudante do seu papel no processo de aprendizagem. É de extrema importância que ele tenha consciência de sua autonomia e papel ativo durante este processo; (...) a diversidade, a conexão conhecimento-reflexão e a integração interdisciplinar são as chaves desta proposta" (LW, estudante participante).

Desta forma, o ADES Jr. veio ao encontro da necessidade de ressignificar papéis no ambiente de ensino ${ }^{7}$. Como primeira demanda para este espaço, os estudantes trouxeram suas angústias e ansiedades diante do ERE e puderam discuti-las com um professor psiquiatra do De- partamento de Medicina Preventiva da universidade. Os estudantes também trocaram informações sobre estratégias de organização dos estudos e uso do tempo, compreendendo sua especial importância durante o ERE.

As atividades, conteúdos, convidados e datas dos encontros do ADES Jr. são apresentadas na tabela 2. O compartilhamento de saberes e vivências entre docentes e discentes evidencia que a necessidade de aprender, de inovar e ensinar é comum a todos os sujeitos envolvidos com a educação. A construção coletiva e solidária de soluções para o enfrentamento da pandemia também precisa alcançar a dimensão do cuidado entre as pessoas. Por isso, iniciativas integradas e colaborativas de trocas de saberes e autodesenvolvimento, como o ADES Jr., apresentam-se como um ponto de apoio importante em meio a tantas incertezas trazidas para o cotidiano das pessoas ${ }^{8}$.

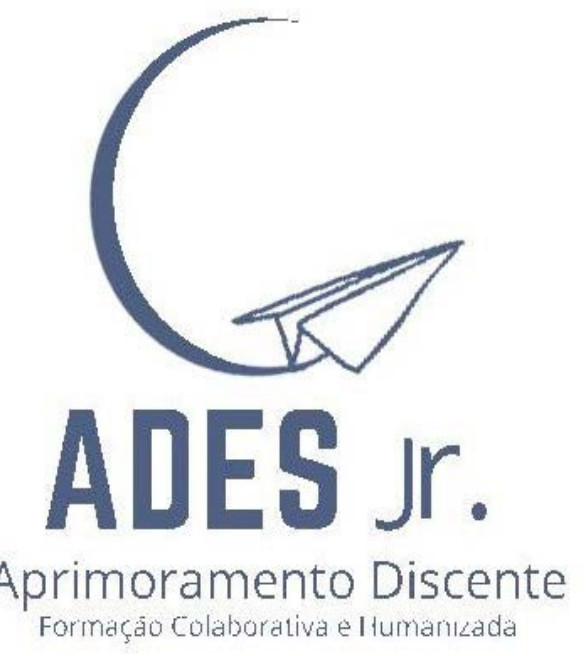

https://instagram.com/adesjr.ufmg?utm_medium=copy_link

Figura 2: Logomarca e perfil do ADES Jr. 
Tabela 2: Temas, conteúdos, datas, convidados e link para acesso para os encontros do ADES jr.

\begin{tabular}{|c|c|c|c|c|}
\hline $\begin{array}{l}\text { TEMAS } \\
\text { /DATA }\end{array}$ & CONTEÚDO & CONVIDADOS & & MODALIDADE \\
\hline \multirow{5}{*}{$\begin{array}{l}\text { O uso do } \\
\text { tempo no } \\
\text { Ensino Re- } \\
\text { moto } \\
\text { Emergencial } \\
/ \\
15 / 10 / 2020\end{array}$} & $\begin{array}{l}\text { Uso do Tempo como foco } \\
\text { no ERE }\end{array}$ & Juliane Corrêa & $\begin{array}{l}\text { Professora As- } \\
\text { sociada da FAE/ } \\
\text { UFMG }\end{array}$ & \multirow[t]{5}{*}{$\begin{array}{l}\text { https://www.sympla.com. } \\
\text { br/o-uso-do-tempo-no-en- } \\
\text { sino-remoto-emergen- } \\
\text { cial_1014045 }\end{array}$} \\
\hline & $\begin{array}{l}\text { Uso do Tempo como foco } \\
\text { no ERE }\end{array}$ & $\begin{array}{l}\text { Helian Nunes de } \\
\text { Oliveira }\end{array}$ & $\begin{array}{l}\text { Psiquiatra, pesqui- } \\
\text { sador e professor } \\
\text { adjunto no curso } \\
\text { de graduação em } \\
\text { Medicina }\end{array}$ & \\
\hline & Apresentação Cultural & $\begin{array}{l}\text { Juliana Casta- } \\
\text { nheira }\end{array}$ & $\begin{array}{l}\text { Aluna de Gradu- } \\
\text { ação - Educação } \\
\text { Física UFMG }\end{array}$ & \\
\hline & $\begin{array}{l}\text { Experiencia Coletiva do } \\
\text { Curso de T.O. na organiza- } \\
\text { ção do tempo no ERE }\end{array}$ & Marcela Nesio & $\begin{array}{l}\text { Aluna de Gradu- } \\
\text { ação - Terapia } \\
\text { Ocupacional UFMG }\end{array}$ & \\
\hline & Planejamento Discente & Sarah Loschi & $\begin{array}{l}\text { Aluna de Gradu- } \\
\text { ação - Terapia } \\
\text { Ocupacional UFMG }\end{array}$ & \\
\hline \multirow{3}{*}{$\begin{array}{l}\text { Design } \\
\text { criativo para } \\
\text { agendas e } \\
\text { planners } \\
\text { / } \\
22 / 10 / 2020\end{array}$} & $\begin{array}{l}\text { Curso Planejando com } \\
\text { Criatividade }\end{array}$ & $\begin{array}{l}\text { Carina Araújo } \\
\text { Coelho }\end{array}$ & $\begin{array}{l}\text { Terapeuta Ocupa- } \\
\text { cional UFMG }\end{array}$ & \multirow{3}{*}{$\begin{array}{l}\text { https://www.sympla. } \\
\text { com.br/design-criati- } \\
\text { vo-para-agendas-e-plan- } \\
\text { ners_1021211 }\end{array}$} \\
\hline & Apresentação Cultural & $\begin{array}{l}\text { Rebeca Araújo } \\
\text { Castro }\end{array}$ & $\begin{array}{l}\text { Aluna de Gradua- } \\
\text { ção - Fisioterapia } \\
\text { UFMG }\end{array}$ & \\
\hline & Apresentação Cultural & $\begin{array}{l}\text { Dara Carolina } \\
\text { Russo }\end{array}$ & $\begin{array}{l}\text { Aluna de gradu- } \\
\text { ação Jornalismo } \\
\text { PUC/Minas }\end{array}$ & \\
\hline \multirow{3}{*}{$\begin{array}{l}\text { Manual de } \\
\text { sobrevi- } \\
\text { vência ERE } \\
\text { - Caloures } \\
\text { desvendan- } \\
\text { do as plata- } \\
\text { formas! } \\
/ \\
30 / 11 / 2020\end{array}$} & Microsoft Teams & $\begin{array}{l}\text { Laura Waters } \\
\text { Franco Milhorato }\end{array}$ & $\begin{array}{l}\text { Aluna de Gradu- } \\
\text { ação Fisioterapia } \\
\text { UFMG }\end{array}$ & \multirow{3}{*}{$\begin{array}{l}\text { https://www.sympla.com. } \\
\text { br/manual-de-sobrevi- } \\
\text { vencia-ere---caloures- } \\
\text { desvendando-as-platafor- } \\
\text { mas_1068491 }\end{array}$} \\
\hline & Apresentação cultural & $\begin{array}{l}\text { Lucas Melo Bar- } \\
\text { bosa }\end{array}$ & $\begin{array}{l}\text { Aluno de Gradu- } \\
\text { ação - Educação } \\
\text { Física UFMG }\end{array}$ & \\
\hline & Apresentação cultural & $\begin{array}{l}\text { Equipe Saran- } \\
\text { deiros }\end{array}$ & $\begin{array}{l}\text { Projeto de Exten- } \\
\text { são EEFFTO UFMG }\end{array}$ & \\
\hline
\end{tabular}




\section{CONHECIMENTOS PRÉVIOS E CO- NHECIMENTOS NOVOS: DANDO SIG- NIFICADO À APRENDIZAGEM}

Melhorar a qualidade e aperfeiçoar são alguns dos sentidos da palavra aprimorar, tomados aqui como objetivos de um processo educativo extensionista para docentes e discentes vinculados a percursos de graduação e pós-graduação na UFMG. Enquanto processo educativo, as ações de aprimoramento foram concebidas visando uma postura ativa de alunos e professores para o desenvolvimento de uma consciência crítica da realidade de aprendizagem e de trabalho em que estão inseridos, reconhecendo as suas necessidades e lacunas no que tange às competências essenciais para o exercício de seus papéis de estudantes, educadores e cidadãos. Valorizando a autonomia de todos os envolvidos, as ações foram fundamentadas no pressuposto de que é a partir das necessidades e do contexto vivido que se cumpre a aprendizagem significativa, que se insere de forma natural na realidade dos sujeitos ${ }^{9}$.

Nesse sentido, a utilização de metodologias que permitam a expressão de um processo ativo de aprendizagem e que repense as práticas baseadas na simples transmissão de conteúdos técnicos, precisam ser incorporadas no cotidiano do ensino superior. Isto é especialmente importante em um cenário onde o encontro presencial não é viável e o processo é, em grande parte, solitário. Muitos professores do ensino superior, no que se refere às práticas pedagógicas, são profissionais que não necessariamente recebem formação específica para desempenhar a função de educador. De maneira geral, é pressuposto que a formação em um curso superior e a pós-graduação em alguma área do conhecimento sejam suficientes para o exercício da docência ${ }^{10}$. Entretanto, observando na prática a maneira como a competência para a docência se concretiza, verificam-se relatos de docentes sobre a dificuldade na mediação de seus conhecimentos para o aprendizado dos alunos, que por outro lado, queixam-se constantemente da didática utilizada por seus professores ${ }^{11,12}$. Ainda que busquem participação em programas de pós-graduação para obtenção de títulos de stricto sensu necessários ao exercício da docência (mestrado e doutorado) muitos professores sentem-se despreparados para assumir seu papel de educadores, visto que os programas de pós-graduação priorizam a capacitação de habilidades relacionadas à pesquisa científica ${ }^{11}$. A dificuldade do exercício da docência é ainda intensificada diante de fatores que modificam a rotina e o modelo dessa tarefa, como no momento em que nos encontramos.

Outros fatores relevantes e para além da pandemia da Covid-19 são: o novo perfil do discente admitido na educação superior ${ }^{13}$, o número de estudantes por sala, as exigências para o aluno egresso e as mudanças nos vários contextos como o da própria educação, das ciências, das tecnologias e da relação dos sujeitos com o conhecimento ${ }^{10}$. Além disso, no Brasil, têm ocorrido mudanças no sistema de ensino com flexibilização e expansão do ensino superior, o que aumenta a necessidade de preparar o docente de maneira eficaz e integral para lidar com diferentes realidades de discentes e formatos educacionais ${ }^{13}$.

Foi a partir deste contexto de experiências prévias comuns de docentes e discentes que foram propostas as atividades do ADES e o ADES Jr. Os projetos impulsionaram reflexões sobre os novos papéis de professores e estudantes no processo formativo, que se tornaram urgentes diante do modelo ERE. Se por um lado o professor precisava inovar e promover o protagonismo e autonomia do estudante, por outro o estudante precisava realmente ser protagonista e buscar a autonomia. A adaptação a novas maneiras de ensinar e aprender exige envolvimento tanto de docentes quanto de discentes, fazendo com que espaços para este aprimoramento tornem-se fundamentais tanto para promover a aproximação com novas ferramentas didático-pedagógicas, quanto para refletir sobre as mesmas e avaliá -las. O espaço da universidade deve ser entendido como lugar de compartilhamento e apoio, seja entre o tradicional binômio professor-aluno, mas para além dessa combinação, sendo possível aprender com os pares e inverter a "hierarquia" para aluno-professor.

Verificamos nessas ações extensionistas aqui compartilhadas, a oportunidade de docentes e discentes perceberem o potencial do trabalho conjunto, transformando relações hierárquicas em recíprocas. A busca por atender as necessidades e realidades de ambos deve envol- 
ver a tecnologia e o contexto social hodierno. O aprendizado de novas habilidades, não apenas relacionadas às questões técnicas que envolvem a formação profissional, como também aquelas concernentes com o viver e as relações humanas, devem ser proporcionadas aos estudantes a partir da percepção de suas demandas e do reconhecimento de sua identidade individual, profissional e interprofissional.

Por esse motivo os projetos ADES buscaram alicerçar aspectos fundamentais da formação do estudante, deixando tangíveis as metas de aprendizagem, o papel e a influência de ambos, docente e discente, o perfil de profissional e cidadão que se almeja e as formas avaliativas do processo. A definição e domínio desses aspectos são potenciais para conduzir o professor na realização de sua tarefa de forma consistente e, portanto, mais facilmente adaptável a contextos diversos; e o aluno a uma aprendizagem realmente significativa ${ }^{14}$.

\section{PERSPECTIVAS FUTURAS}

Tendo como premissa que o primeiro desafio para o docente do ensino superior é o desafio ético de estar ciente do seu compromisso para com o estudante e a sociedade, assumindo seu papel de forma integral (pesquisa, extensão e docência), acreditamos que o ADES-FIT precisa ampliar suas atividades. Precisamos estimular continuamente o professor a investir na aquisição de habilidades pedagógicas que possam auxiliá-lo no processo ensino- aprendizagem. São necessários momentos de reflexões e capacitações para o uso de ferramentas que auxiliem o professor no cumprimento de sua função. É preciso ter em mente que este professor aprendiz também necessita ser protagonista de sua formação e que a oferta de possibilidades deve emergir das demandas que se apresentam em seu contexto para garantir a motivação e o aprendizado significativo. Frente ao novo perfil de estudantes universitários e a recente realidade da educação, que possibilita novas oportunidades para o ensino à distância, as experiências vivenciadas pelos docentes em suas próprias telas de aula tornam o processo ensino-aprendiza- gem um objeto de interesse diante de tamanhos desafios. Ao mesmo tempo, a sobrecarga de trabalho, para muitos incrementada pelas tarefas domésticas, apresenta-se como uma barreira para o investimento em momentos de aprimoramento. O ADES precisará mobilizar estratégias que possam atender a diversidade de contextos vivenciados pelo corpo docente e superar a inexistência de incentivo formal aos docentes universitários para sua formação pedagógica.

Nos parece uma estratégia interessante propor discussões sobre temas relacionados à educação em ambos os projetos, ADES-FIT e ADES Jr., primeiramente, de forma separada, e em um segundo momento de forma conjunta, tornando possível evidenciar duas visões do mesmo objeto, que de fato diz respeito a ambos os atores do processo de formação. Esta aproximação permitirá facilitar o relacionamento professor-estudante, cerne essencial e ao mesmo tempo sensível neste processo à distância, que tem ressignificado o papel docente, transformando percepções. A aproximação dos dois projetos também poderá criar um ambiente colaborativo para elaboração da matriz de competências para o curso com a participação discente, além de viabilizar decisões democráticas sobre a implementação de processos de avaliação programática no futuro.

\section{CONSIDERAÇÕES FINAIS}

Para viabilizar a continuidade do ensino superior durante a pandemia do coronavírus estão sendo impostas mudanças substanciais nos modelos educacionais. Novas soluções são necessárias e demandam um esforço coletivo de toda a comunidade acadêmica. Quanto maior a clareza acerca dos aspectos que precisam ser desenvolvidos e aprimorados, maiores as chances de propormos ações que resultem no aperfeiçoamento dos processos de formação. A extensão universitária cumpre seu papel nesse sentido. Os projetos aqui compartilhados são um exemplo de como os contextos adversos podem ser momentos importantes para movimentar ideias e revelar conhecimentos já produzidos e a serem estudados. A adequada caracterização das condições existentes nas instituições ${ }^{15}$ para estudantes e profes- 
sores, e as ferramentas de apoio produzidas e compartilhadas entre a comunidade acadêmica é chave para as mudanças inevitáveis e irreversíveis da educação no ensino superior.

\section{REFERÊNCIAS:}

1. Maria E, Regueiro G, Cristine E, Mateus L, Gonçalves C, Maia $M$, et al. Ensino mediado por tecnologias no curso de Fisioterapia do Centro Universitário Barão de Mauá durante o período de pandemia da COVID-19 Teaching mediated by technologies in the Physiotherapy course of Barão de Mauá University Center during the COVID-19 pa. Rev Interdiscip Saúde e Educ. 2020;1(1):107-19. Available from: https://periodicos.baraodemaua.br/index.php/cse/article/view/36/24

2. Valente GSC, Moraes ÉB de, Sanchez MCO, Souza DF de, Pacheco MCMD. O ensino remoto frente às exigências do contexto de pandemia: Reflexões sobre a prática docente. Res Soc Dev . 2020 Sep 9 ;9(9). Available from: https://www.rsdjournal.org/index.php/rsd/article/view/8153

3. Silva JA de O, Rangel DA, Souza IA de. Docência superior e ensino remoto. Rev Docência do Ensino Super . 2020 Nov $28 ; 10: 1-19$. Available from: https://periodicos.ufmg.br/index.php/rdes/article/view/24717

4. Rezende IM de. Os reflexos de um mundo que (quase) parou por causa de um vírus e a reinvenção das instituições de ensino para (con)viver com ele. Rev Docência Ens Sup . $2020 ; 10(e 025195): 1-4$. Available from: https://periodicos.ufmg.br/index.php/rdes/article/ view/25195/19705

5. Castaman AS, Rodrigues RA. Educação a Distância na crise COVID - 19: um relato de experiência. Res Soc Dev . 2020 Apr 23;9(6):e180963699. Available from: https://rsdjournal.org/index.php/rsd/article/view/3699

6. Teles G, Mara Romualdo Soares D, de Lima L, Carlos Loureiro R. Docência e Tecnologias Digitais na Formação de Professores: Planejamento e Execução de Aulas por Licenciandos Teaching and Digital Technologies in Teacher Education: Planning and Execution of Lessons by Graduates. Brazilian J Technol Braz J Technol . 2020 May 2;3(2):73-84. Available from:
https://www.brazilianjournals.com/index.php/BJT/ article/view/9459

7. Chiarella T, Bivanco-Lima D, Moura J, Marques MC, Marsiglia R. Aprendizagem na Educação Médica The Pedagogy of Paulo Freire and Medical Education. Rev Bras Educ Med. 2015;39(3):418-25. Available from: http://dx.doi. org/10.1590/1981-52712015v39n3e02062014

8. Alvim CG, Medeiros AM De, Freire C, Morais DA, Ruas CM, Vilaça ÊL, et al. SEÇÃO ESPECIAL : DOCÊNCIA NO ENSINO SUPERIOR EM TEMPOS DE PANDEMIA CURSOS DA SAÚDE : INTEGRAÇÃO E RESPONSABILIDADE SOCIAL NO ENFRENTAMENTO DA PANDEMIA. 2020;1-21.

9. Freire P. Carta de Paulo Freire aos professores. Estud Avançados. 2001 Aug ;15(42):259-68. Available from: http://www.scielo.br/scielo.php?script=sci_arttext\&pi$\mathrm{d}=\mathrm{S} 0103-40142001000200013 \& \operatorname{lng}=\mathrm{pt} \& \mathrm{t} \operatorname{lng}=\mathrm{pt}$

10. Pachane GG, Pereira EMDA. a Importância Da Formação Didático-Pedagógica E a Construção De Um Novo Perfil Para Docentes Universitários. Rev Iberoam da Educ. 2004;33(1681-5653):1-13.

11. CUNHA AM de O, BRITO TT, CICILLINI GA. Dormi aluno (a)... acordei professor (a): interfaces da formação para o exercício do ensino superior. 29a Reun Anu da ANPEd 2006 Caxambu. 2006; Available from: http://29reuniao. anped.org.br/trabalhos/trabalho/GT11-2544--Int.pdf

12. Pádua GD. "Esses professores precisam de reciclagem": A avaliação dos estudantes da UFU sobre as práticas didático-pedagógicas dos docentes. DiversaPratica. 2012;01(1):135-52. Available from: https://dspace.ups. edu.ec/bitstream/123456789/5224/1/UPS-QT03885.pdf

13. Torres S, Otoni DL, Bourdieu P. MUDANÇAS NO PERFIL DOS ESTUDANTES DA UFMG : DESAFIOS PARA A PRÁTICA DOCENTE CHANGES IN THE PROFILE OF UFMG STUDENTS : CHALLENGES FOR THE TEACHING PRACTICE. 2020;1-21.

14. Esteves M. Para a excelência pedagógica do ensino superior. Sisifo - Rev Ciências da Educ . 2008;(7):101-10. Available from: http://sisifo.fpce.ul.pt

15. Gusso HL, Archer AB, Luiz FB, Sahão FT, Luca GG de, Henklain MHO, et al. ENSINO SUPERIOR EM TEMPOS DE PANDEMIA: DIRETRIZES À GESTÃO UNIVERSITÁRIA. Educ Soc. 2020;41:2020. Available from: https://doi. org/10.1590/ES.238957 


\section{Agradecimentos:}

As autoras gostariam de agradecer à discente Laura Waters Franco Milhorato pelo seu empenho e dedicação na concepção do projeto Aprimoramento Discente do Ensino Superior - ADES Jr., a aluna de pós-graduação em Ciências da Reabilitação Bárbara Alice Junqueira Murta pela disponibilidade em elaborar as divulgações dos encontros virtuais do ADES-FIT e a todos os convidados que prontamente aceitaram o convite em partilhar seus saberes em prol de uma educação superior melhor.

Corresponding Author:

Danilo Donizetti Trevisan, RN, PhD, Adjunct Professor.

ddtrevisan@ufsj.edu.br

Editor:

Prof. Dr. Marcelo Riberto

Recebido: 30/04/2021

Aprovado: 13/07/2021

(c) (i) Este é um artigo publicado em acesso aberto (Open Access) sob a licença Creative 